\title{
A Wideband Radar for High-Resolution Mapping of Near-Surface Internal Layers in Glacial Ice
}

\author{
Pannirselvam Kanagaratnam, Member, IEEE, Siva Prasad Gogineni, Fellow, IEEE, \\ Vijay Ramasami, Student Member, IEEE, and David Braaten
}

\begin{abstract}
Snow accumulation rate is an important parameter in determining the mass balance of polar ice sheets. Accumulation rate is currently determined by analyzing ice cores and snow pits. Inadequate sampling of the spatial variations in the ice sheet accumulation has resulted in accumulation rate uncertainties as large as $24 \%$. We designed and developed a $600-900-\mathrm{MHz}$ airborne radar system for high-resolution mapping of the near-surface internal layers for estimating the accumulation rate of polar ice sheets. Our radar system can provide improved spatial and temporal coverage by mapping a continuous profile of the isochronous layers in the ice sheet. During the 2002 field season in Greenland, we successfully mapped the near-surface layers to a depth of $200 \mathrm{~m}$ in the dry-snow zone, $120 \mathrm{~m}$ in the percolation zone, and $20 \mathrm{~m}$ in the melt zone. We determined the water equivalent accumulation rate at the NASA-U_1 site to be $34.9 \pm 5.1 \mathrm{~cm} /$ year from 1964 to 1992. This is in close agreement with the ice-core derived accumulation rate of $34.6 \mathrm{~cm} /$ year for the same period.
\end{abstract}

Index Terms-Airborne radar, arctic regions, frequency-modulated continuous wave, snow.

\section{INTRODUCTION}

$\mathbf{S}$ EA LEVELS rose by about $15 \mathrm{~cm}$ over the last century and are reported to be a strong indicator of global climate change [1]. The Intergovernmental Panel on Climate Change (IPCC) [2] projects that sea levels will rise further by about $50 \mathrm{~cm}$ over the next 100 years. A sea level rise of this magnitude would have devastating impacts on coastal regions, with erosion, loss of land and property, increased risk of storm surges, vulnerability of coastal ecosystems, and saltwater intrusion [2]. The impact will be very severe on developing countries because of the high costs associated with adapting and responding to these changes. Because of the fear that the rising sea level will submerge Tuvalu, a Pacific island nation, it was recently evacuated [3].

About $50 \%$ of the current sea level rise is attributed to thermal expansion of the ocean and the melt of mountain glaciers [4]. There is considerable uncertainty as to the role of polar ice sheets in current and future sea level rise. To assess the role of these ice sheets, an improved knowledge of their mass balance is required. The mass balance can be determined either by comparing input flux-accumulation rate-with total ice lost through calving and melting, or by measuring changes in ice sheet surface elevation.

Manuscript received December 11, 2002; revised December 4, 2003. This work was supported by the National Aeronautics and Space Administration under Grants NGT5-50219 and NAG5-12439.

The authors are with the Radar Systems and Remote Sensing Laboratory, Information and Telecommunication Technology Center, University of Kansas, Lawrence, KS 66045 USA (e-mail: gogineni@ittc.ku.edu).

Digital Object Identifier 10.1109/TGRS.2004.823451
Accumulation rate is a key variable in interpreting surface elevation measurements and in determining the mass input [5]-[7]. It is currently determined from ice cores and pits [8], and there are large errors in the estimated accumulation rate for areas with sparse measurement distribution. For the Greenland ice sheet, Ohmura and Reeh [9] generated an accumulation map using data from 251 pits and cores and precipitation measurements from 35 meteorological stations located in coastal regions. The accuracy of this map is a function of the spatial location of the data points. Also, Ohmura and Reeh [9] reported that an inherent accumulation rate uncertainty of $20 \%$ in their map was due to the inconsistency between meteorologically determined precipitation and glaciologically determined accumulation. Later, more than 75 different cores from 50 distinct locations were obtained in the National Aeronautics and Space Administration (NASA) Program for Arctic Regional Climate Assessment (PARCA) initiative. Information from these cores was used to generate an updated map of accumulation over the Greenland ice sheet. Bales et al. [10], [11] report that the uncertainty in accumulation is still on the order of $24 \%$ for certain areas, largely because of spatial variability.

To obtain improved spatial and temporal coverage and reduce errors in the long-term accumulation rate, we have been exploring the application of high-resolution radars for generating continuous profiles of dated layers in the ice. Interannual accumulation and volcanic and melt events cause these layers. Annual accumulation and melt events register a change in the density, whereas volcanic events produce a change in conductivity [12]. By mapping shallow internal layers and combining these data with published information on density and thickness, we can estimate the accumulation rate [13]. The spatial coverage possible with an airborne system can be used to reduce the errors due to local variability and study the effect of such variability by collecting data from the near-surface layers over distances greater than several ice thicknesses.

The application of HF and VHF airborne radars to measure ice thickness and internal layers is well established, and a brief survey of these systems is presented in [14]. Reflection profiles from ice-sounding radar systems show many internal ice reflections between the bedrock and the surface. We developed a wideband frequency-modulated continuous wave radar operating over the frequency range from $600-900 \mathrm{MHz}$ and successfully demonstrated that it can map near-surface internal layers with a resolution of less than $1 \mathrm{~m}$ to the desired depth. We have collected a large volume of data with this system on the Greenland ice sheet. In this paper, we discuss the design and simulation of the radar, test results from simulated targets, and analyze experimental results. 


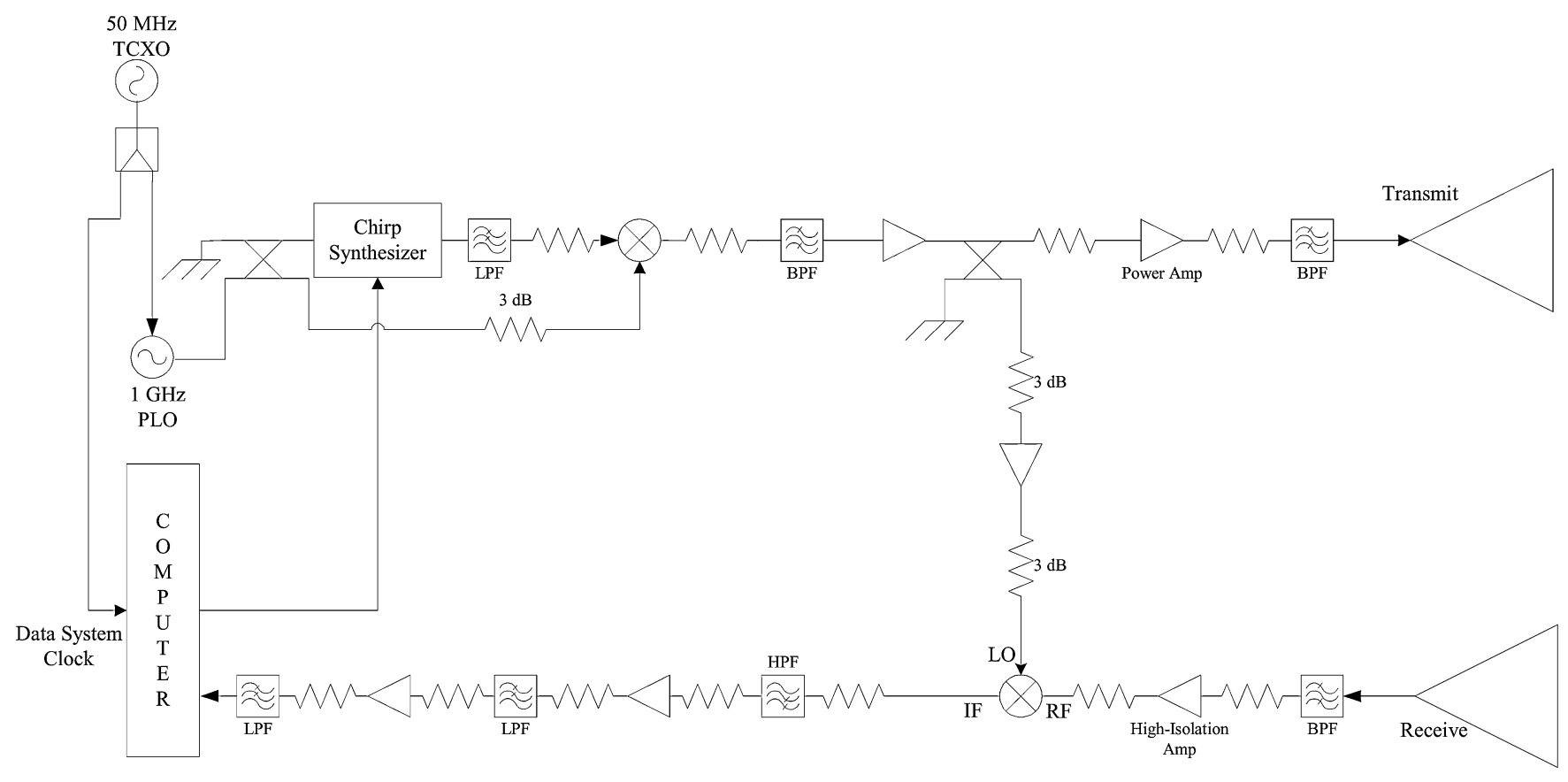

Fig. 1. Block diagram of improved airborne radar system.

\section{SYSTEM DESCRIPTION}

Fig. 1 shows the wideband radar block diagram. A 1-GHz oscillator, which is phase-locked to a $50-\mathrm{MHz}$ temperaturecompensated crystal oscillator (TCXO), provides the clock signal for a direct digital synthesizer (DDS). The DDS generates the transmit chirp signal over the frequency range from 100-400 MHz. An upconverter, using the 1-GHz source as the local oscillator, converts the 100-400-MHz DDS output to the transmit signal frequency range of 600-900 MHz. A bandpass filter, which follows the upconverter, rejects the upper sideband and other unwanted signals. A driver amplifier increases the filtered signal to a level required to drive the power amplifier. With a directional coupler, which follows the driver amplifier, a sample of the transmit signal is tapped off to serve as the local oscillator for a mixer in the receiver. This mixer generates beat frequencies proportional to range by combining received signals with a sample of the transmitter signal. The power amplifier increases the transmit signal level to $2 \mathrm{~W}$. We used a wideband power amplifier that operates over the frequency range 500-1000 $\mathrm{MHz}$ with a voltage standing wave radio (VSWR) variation of 2:1 over its operating range. We padded the power amplifier with $3-\mathrm{dB}$ attenuators to reduce mismatch at its input and output ports. The output $3-\mathrm{dB}$ attenuator reduces the transmit signal level to $1 \mathrm{~W}$. The signal is then propagated to free space with a bandpass filter and a transverse electromagnetic (TEM) wave horn antenna. TEM horn antennas are used for transmit as well as receive signals. They have beamwidths of $45^{\circ}$ at $600 \mathrm{MHz}$ and $30^{\circ}$ at $900 \mathrm{MHz}$.

The receive antenna collects reflected signals, and these signals are passed through a bandpass filter to ensure that no out-of-band signals are coupled into the receiver. A low-gain $(10 \mathrm{~dB})$ high-isolation amplifier, which has $50 \mathrm{~dB}$ of reverse isolation, is used as the first-stage amplifier. We used a low-gain amplifier with high reverse isolation to minimize the local oscillator signal, which is coupled into the RF port of the mixer and radiated through the receive antenna. In the mixer, the received signal is combined with a sample of the transmitter signal to generate beat frequencies proportional to the range. For attenuating the antenna feedthrough signal, we filtered the beat frequency signal with a third-order Gaussian highpass filter. The design and selection of this filter is crucial to proper functioning of the radar. It must provide high attenuation to the low-frequency antenna feedthrough signals without excessive ringing. We designed it to attenuate the leakage signal by $60 \mathrm{~dB}$ with a fast settling time. We designed and constructed a third-order Gaussian filter [15], [16] and have simulated and measured its frequency response. The cutoff and desired attenuation at $0.5 \mathrm{MHz}$ closely matches the design specifications. The $90 \%$ settling time for the filter is $50 \mathrm{~ns}$, and the maximum overshoot value is $-25 \mathrm{mV}$.

We then used an amplifier with a high 1-dB compression point $(20 \mathrm{dBm})$ to amplify the IF signal. The high $1-\mathrm{dB}$ compression point is needed to prevent amplifier saturation by the upper sideband signal generated in the mixer. The amplified signal is then lowpass filtered to reject the upper sideband and the LO leakage signal. A lowpass filter at this stage ensures that the strong sideband and leakage signals do not saturate the amplifier in the following stage. The beat-frequency signals are further amplified to use the full A/D dynamic range. An antialiasing filter with a cutoff frequency of $21 \mathrm{MHz}$ is used to prevent spurious signals from folding over into the desired spectrum.

To optimize the radar's performance, we used Agilent's EEsof to simulate the system response. We performed these simulations using the scattering parameters of components to be used in the radar. We used manufacturer-supplied data files for some devices. For other devices for which there were no 


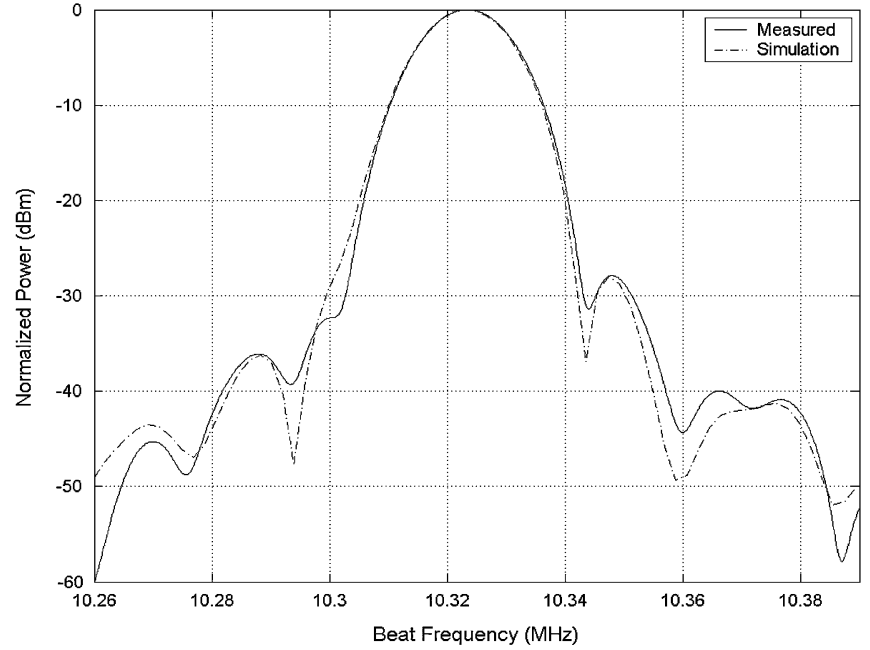

Fig. 2. Comparison between measured and simulated delay line response.

manufacturer data, we measured $S$-parameters in the laboratory using a network analyzer. We also digitized the output of the STEL-9949 DDS with an oscilloscope that had an eight-bit A/D converter and used it to represent the chirp signal. Fig. 2 shows a comparison of our simulation and measured responses. The data are weighted with a Hanning function for reducing range sidelobe. The $3-\mathrm{dB}$ main lobe width is about $16 \mathrm{kHz}$, corresponding to a one-way electrical range of about $120 \mathrm{~cm}$. Thus, free-space radar resolution is about $60 \mathrm{~cm}$. The first left sidelobe peak is $32 \mathrm{~dB}$ below the main lobe, but the first right sidelobe peak is only $28 \mathrm{~dB}$ below the main lobe. This is $4 \mathrm{~dB}$ higher than that for a signal weighted with a Hanning function. The higher sidelobe is the result of a mismatch between a cable and an adapter, which are used to connect the delay line to the receiver.

\section{TARGET SIMULATOR}

Because of interference from cell phones and television stations operating in the UHF range, we could not test the radar using external calibration targets. To avoid repeated and expensive trips to the polar regions for testing and optimizing radar performance, we designed and developed a target that simulates antenna feedthrough and reflections from the air/firn interface and internal layers. We developed it using radio frequency/optical (RF/O) transceivers and fiber-optic delay lines. We used a semirigid microwave line with delay of $167 \mathrm{~ns}$ to match the actual path between the antennas. We upconverted the RF signal with an RF/O transceiver. We passed the upconverted signal through an optical-fiber delay line to simulate a 1000-m two-way distance between the aircraft and the ice. Using a couple of RF couplers and a short cable, which simulates delay of about $50 \mathrm{~cm}$, we constructed a feedback loop to simulate reflections from near-surface internal layers. We downconverted optical signals into the RF range using an optical/RF transceiver and combined the downconverted $\mathrm{RF}$ signals with the signal generated to represent the antenna feedthrough signal. A more detailed description of the target simulator is available in [17].

\section{Signal PROCESSING}

We removed the DC offset in the time series data, applied a Hanning window to reduce the range sidelobes in the frequency domain, and Fourier transformed the windowed data to obtain range profiles. We then lowpass filtered these profiles to determine the amount of gain needed to correct for the $1 / \mathrm{r}^{2}$ power falloff with range. The range profiles were then multiplied with the inverse of the lowpass filtered data to obtain the gain-corrected responses. All the range profiles along the traverse were compiled to produce an echogram for the transect.

The theoretical radar range resolution with a bandwidth of $300 \mathrm{MHz}$ in free space is $0.5 \mathrm{~m}$. Because we applied a Hanning window to reduce range sidelobes, the range resolution is reduced to about $60 \mathrm{~cm}$ in free space, and the actual resolution is the free-space value divided by index refraction in firn, which varies as a function of depth. The horizontal resolution for a smooth surface as determined by the first Fresnel zone is about $11.2 \mathrm{~m}$.

\section{EXPERIMENT AND RESULTS}

The University of Kansas, as a part of the NASA PARCA initiative, has been performing ice thickness measurements from the NASA P-3 aircraft over the Greenland ice sheet for several years. We have been making these measurements using a coherent radar [18], while the NASA team has been conducting surface elevation measurements using a laser altimeter [19]. During the May 2002 field missions, we installed the wideband radar along with the other systems in the P-3 for mapping the internal layers. The radar system and computer were installed in a rack by the wing of the aircraft. The nadir-looking TEM horn antennas were installed in the bomb bay of the aircraft. A low-loss RF cable was used to connect the transmitter and receiver to the antennas. The aircraft flew about $500 \mathrm{~m}$ above the surface of the ice at a speed of about $130 \mathrm{~ms}^{-1}$.

The Greenland ice sheet is divided into four major zones (facies), viz., the dry snow, percolation, wet snow (or soaked), and ablation zones [20], as depicted in Fig. 3. The dry-snow zone is defined as the region where there is negligible melting or percolation even in the summer. In the percolation zone, there is surface melting. This melt water percolates into the snow and refreezes at temperatures below $0{ }^{\circ} \mathrm{C}$. The wet snow zone is characterized by surfaces with wet or saturated snow at a temperature of $0{ }^{\circ} \mathrm{C}$. In the ablation zone, the snow that accumulates during the winter melts away during the summer. We collected data over the dry snow, percolation, and wet snow regions during the 2002 field season. In this section, we present the data obtained from these regions and discuss how we derived the accumulation rate from the radar data.

Fig. 4(a) shows the results from internal layers observed over a $300-\mathrm{km}$ traverse in the dry-snow zone of North Greenland. The results show that we can map internal layers up to a depth of about $200 \mathrm{~m}$. These layers are continuous across the entire $300-\mathrm{km}$-long flight line. The depth scale on these figures is relative to the height of the aircraft and is not corrected for the velocity of propagation in firn. Fig. 4(b) shows measurements along a flight path starting in the percolation region, where meltwater percolates into the snowpack (left-hand side), and transitioning into the dry-snow region (right-hand side), where sig- 


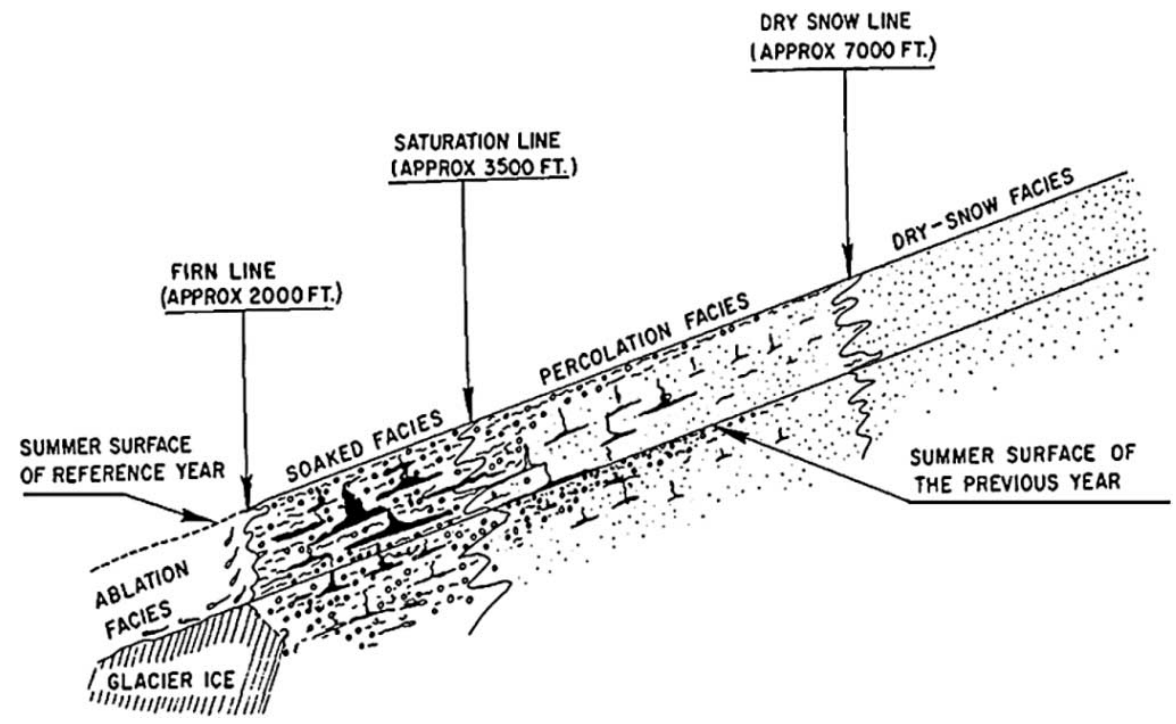

Fig. 3. Accumulation zones (facies) in the Greenland ice sheet [8], [19]. Fig. 4(a)-(c) shows dry-snow, percolation, and wet-snow facies.

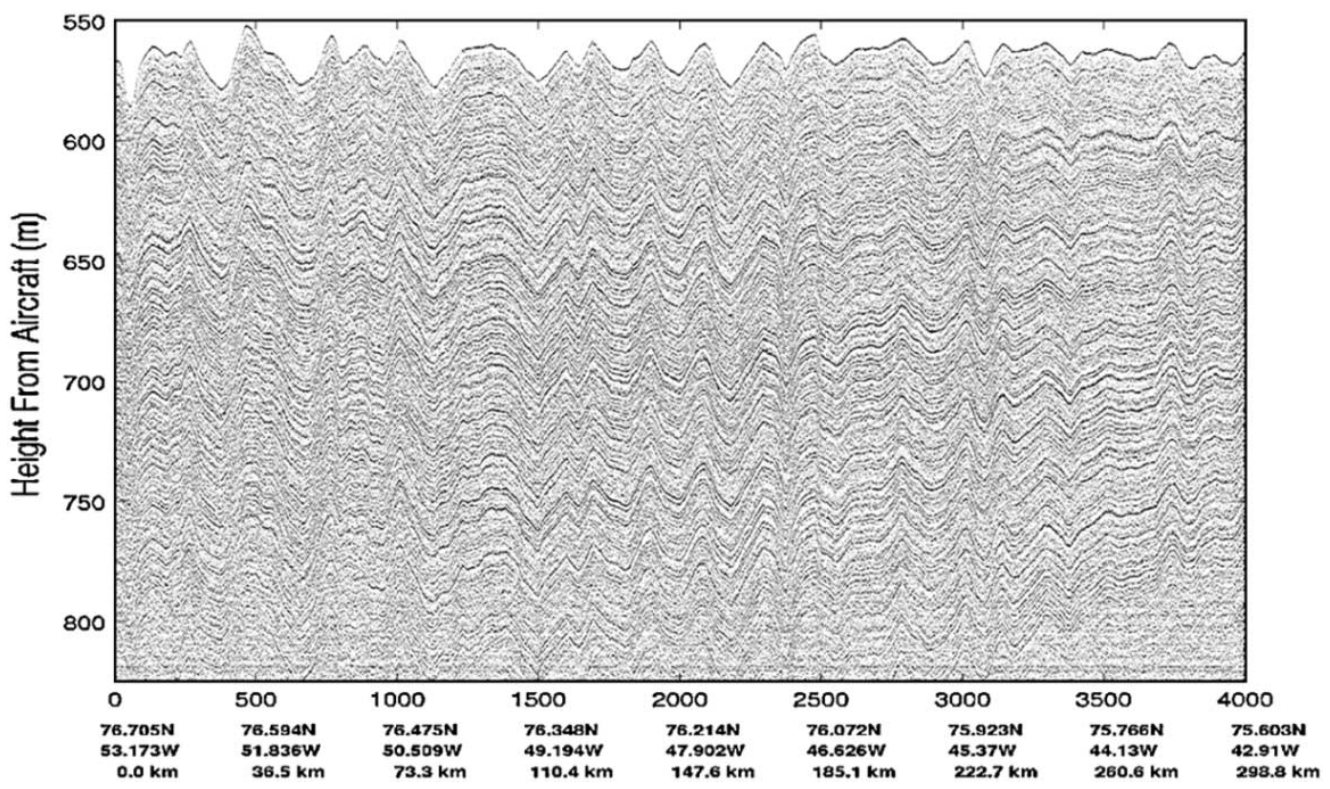

(a)

Fig. 4. (a) Internal layers observed over a 300-km traverse over the Greenland ice sheet.

nificant melting does not occur. Only a few layers can be observed in the percolation region in comparison to the dry-snow region. This is due to the presence of wet snow (making the medium lossy) and numerous ice layers that create a strong dielectric contrast and prevent the transmission of signals further into the ice sheet. Several strong reflections can be observed in the top $30 \mathrm{~m}$ that are likely due to ice layers resulting from the refreezing of the meltwater during the transition from summer to winter seasons. Fig. 4(c) shows the layers that were observed in the wet-snow zone. This zone is characterized by surfaces with wet or saturated snow at a temperature of $0{ }^{\circ} \mathrm{C}$. Because the wave penetration is severely limited by the wet surface, we can only observe a few layers to a depth of about $20 \mathrm{~m}$. These layers allow us to determine the accumulation rate over a period of about 20 years.
Table I shows the depth of several annual horizons dating back to 1961 as determined by isotopic analysis of the ice core. It also gives the depth of the corresponding radar-measured horizon for that year, as well as the difference between the two. The results show that our dating uncertainties are within $\pm 1.5 \mathrm{~m}$ of the core-determined depths. We computed the accumulation rate at this location based on the radar-determined depths. Table II shows the computed water-equivalent accumulation rate per year over the periods indicated in column one. The average density of the firn layer over the indicated period was used to calculate the accumulation rate over the same period using the following equation:

$$
\text { Accumulation rate, } A=\frac{\mathrm{dR}}{\mathrm{dt}} \frac{\rho_{\text {layer }}}{\rho_{\text {water }}}
$$




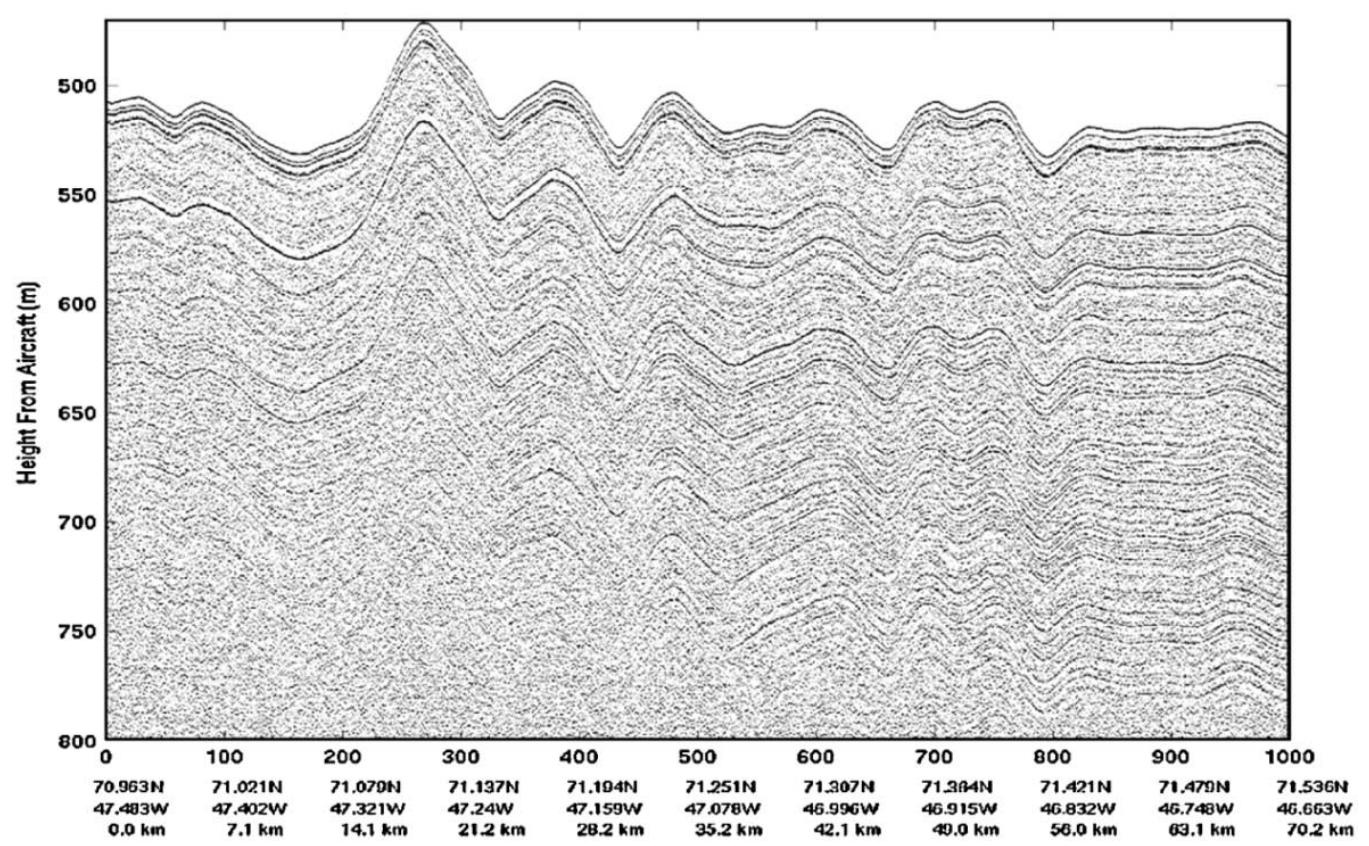

(b)

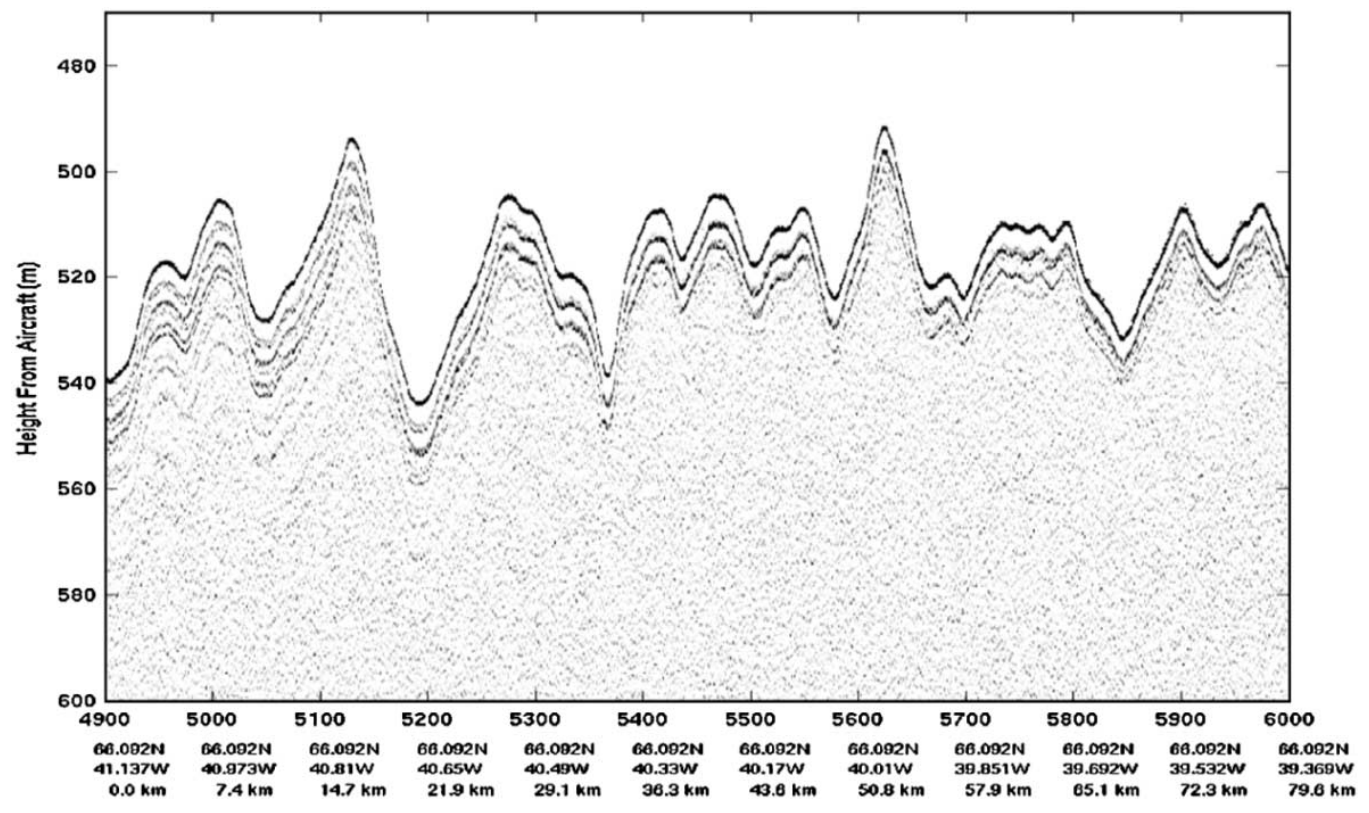

(c)

Fig. 4. (Continued.) (b) Transition from percolation to dry-snow zone. (c) Layering over the wet-snow zone.

where $\mathrm{dR} / \mathrm{dt}$ is the change in thickness over time, $\rho_{\text {layer }}$ is the average density between the two layers, and $\rho_{\text {water }}$ is the density of water.

We collected data along a flight line that included the NASA-U_1 ice core site $\left(73.84^{\circ} \mathrm{N}, 49.49^{\circ} \mathrm{W}\right)$. The ice core record consists of depth and its corresponding age and density [21]. The density data are sampled at nonuniform intervals with a mean sampling interval of $1.04 \mathrm{~m}$ and a variance of $0.05 \mathrm{~m}$. We determined the dielectric profile from the density data using the empirical equation $\varepsilon_{r}=1+1.7 \rho+0.7 \rho^{2}$ [21]. From the dielectric profile, we computed the reflection profile of the ice sheet at the core location by modeling each of its layers as a transmission line. We convolved this reflection profile with the point spread function of an ideal linear FM waveform with the same bandwidth and duration of the accumulation radar transmit waveform to obtain a beat frequency signal. We applied a Hanning window to the beat frequency signal to reduce range sidelobes and Fourier transformed the data to obtain a simulated range profile. Using the density data from the ice core, we computed a depth scale for the simulated and measured radar profiles. Fig. 5 shows both profiles as a function of the depth.

In comparing the ice core and radar data, we must compensate for the seven-year difference between the time the ice core was retrieved (1995) and the time the radar measurements were made (2002). We did this by subtracting a depth equivalent to seven years' accumulation from the radar measurements. We used the depth-age data from the ice core to determine the cor- 
TABLE I

DEPTH ERROR BETWEEN RADAR DATA AND CORE DATA

\begin{tabular}{c|c|c|c}
\hline Year & Core Depth (m) & Radar Depth (m) & Differrence (m) \\
\hline 1992 & 6.9 & 6.5 & -0.4 \\
\hline 1990 & 9.6 & 8.3 & -1.3 \\
\hline 1986 & 11.6 & 11.3 & -0.3 \\
\hline 1983 & 13.5 & 12.4 & -1.1 \\
\hline 1979 & 15.5 & 15.1 & -0.4 \\
\hline 1975 & 17.3 & 17.3 & 0 \\
\hline 1973 & 19.1 & 18.9 & -0.2 \\
\hline 1971 & 21.1 & 19.8 & -1.3 \\
\hline 1969 & 22.1 & 21.2 & -0.9 \\
\hline 1967 & 23.1 & 22.0 & -1.1 \\
\hline 1964 & 24.0 & 24.0 & 0 \\
\hline 1961 & 25.0 & 25.3 & 0.3 \\
\hline
\end{tabular}

TABLE II

COMPuTEd ACCuMUlation Rate From Radar Data

\begin{tabular}{c|c|c|c}
\hline Year & $\begin{array}{c}\text { Measured } \\
\text { Thickness } \\
(\mathbf{m})\end{array}$ & $\begin{array}{c}\text { Avg. Density } \\
\left(\mathbf{k g} / \mathbf{m}^{\mathbf{3}}\right)\end{array}$ & $\begin{array}{c}\text { Water equivalent } \\
\text { accumulation } \\
(\mathbf{c m} / \mathbf{y r} .)\end{array}$ \\
\hline $1990-1992$ & 1.7 & 500.8 & 42.6 \\
\hline $1986-1990$ & 3.0 & 526.7 & 39.5 \\
\hline $1983-1986$ & 1.2 & 546.0 & 21.8 \\
\hline $1979-1983$ & 2.7 & 560.0 & 37.8 \\
\hline $1975-1979$ & 2.1 & 581.6 & 30.5 \\
\hline $1973-1975$ & 1.7 & 598.5 & 50.9 \\
\hline $1971-1973$ & 0.9 & 608.0 & 27.4 \\
\hline $1969-1971$ & 1.4 & 612.7 & 42.9 \\
\hline $1967-1969$ & 0.8 & 618.6 & 24.7 \\
\hline $1964-1967$ & 2.0 & 624.8 & 41.6 \\
\hline $1961-1964$ & 1.3 & 632.3 & 27.4 \\
\hline & & Mean & $34.9 \pm 5.1$ \\
\hline
\end{tabular}

responding average seven-year depth, which was about $5.6 \mathrm{~m}$ at the NASA-U site. In addition, the ice core density data were sampled from a depth starting at $1 \mathrm{~m}$ in 1995 . As a result, the offset between the radar and the ice core data was $6.6 \mathrm{~m}$. After accounting for the offset, we qualitatively related peaks in the simulated profile with a corresponding peak in the measured profile, s shown in Fig. 5. Note that the measured data contain more peaks than in the simulated data, and this can be attributed to the coarse resolution ice core density data. Our simulations were based on snow density measurements that were averaged over a depth of about $1 \mathrm{~m}$, whereas the radar data have a theoretical range resolution of $0.60 \mathrm{~m}$ in free space after applying a Hanning window. Without higher resolution ice core density data, the magnitude of the simulated reflections does not allow for a true one-on-one comparison with the radar reflections. The radar data also do not show many of the deep nulls seen in the simulated data. This is because the simulations did not include surface and volume scattering effects, whereas the lower threshold is set by these two effects in the experimental data. A part of the uncertainty in accumulation rate determination is the result of our inability to exactly match the first reflection in the simulated data with that in the measured data. This error can

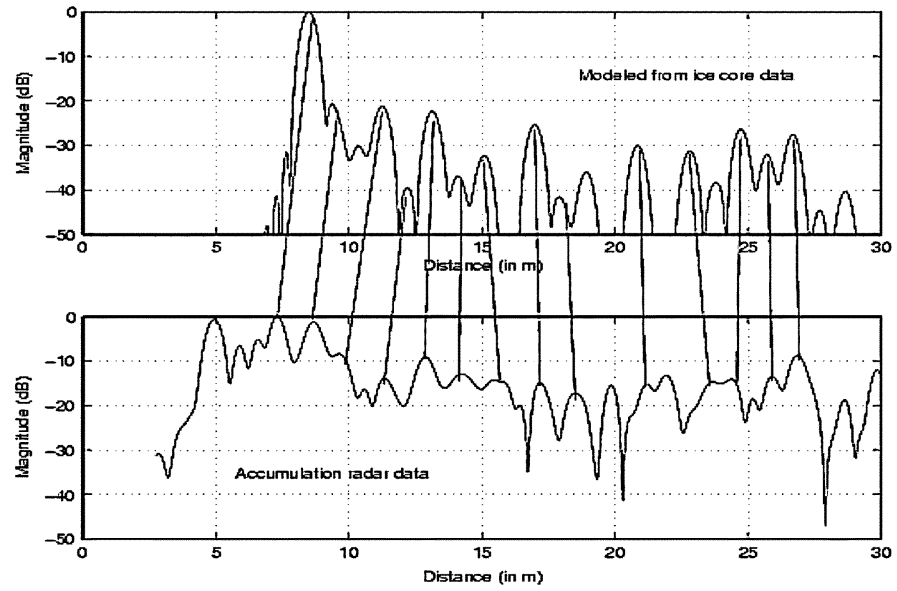

Fig. 5. Simulated and measured radar response as a function of depth at the NASA-U core site. The qualitative comparison of the plots is indicated using lines that connect the peaks of both the plots.

be eliminated by acquiring a core simultaneously with the radar measurements.

The average accumulation rate between 1964 and 1992 was determined by taking a weighted sum of the accumulation rate for each of the periods indicated in column one and dividing it by the total number of years over this period. We found the water equivalent accumulation rate to be $34.9 \pm 5.1 \mathrm{~cm} /$ year. The water equivalent accumulation rate over the same period was also computed from the ice core by Anklin et al. [22] as $34.57 \mathrm{~cm} /$ year. These results agree very well with our radar-measured accumulation rate. The computation of the uncertainty in our accumulation rate estimate has been detailed in [13]. The primary sources of error in the computation of accumulation rate are the uncertainties in the range measurements and the density profile assumptions (or measurements, if available). We estimate that the error in our assumed density profile is $\sim 5 \%$, with the range uncertainty partly dependent on this error [13]. In addition, there is also an absolute uncertainty of $\pm 0.5 \mathrm{~m}$ due to the vertical range resolution of the radar. The uncertainty in the accumulation rate is also dependent on the averaging period, decreasing as the averaging period increases.

The ability to track layers over very long flight paths, and hence determine the spatial variability of accumulation rate, is a significant advance in reducing the uncertainty of the magnitude of mass input to the ice sheet. We have determined accumulation rate as a function of distance along the flight path by identifying several layers in the echogram that we had previously associated with the simulated range profile and tracking these layers along the flight path. Four of these layers are shown as bold, dark lines in Fig. 6. We measured the ice thickness between adjacent layers and computed the accumulation rate (1) along the flight path.

Fig. 7 shows the results of this analysis, with the accumulation rate for different years given at various distances from the core site. Generally, the period from 1983 to 1990 had the lowest accumulation rate $(0.3045 \pm 0.017 \mathrm{~m} / \mathrm{year})$ and the period between 1979 and 1983 had the highest accumulation rate $(0.3904 \pm 0.027 \mathrm{~m} /$ year). The average accumulation rate for each location is also given in Fig. 7.

These preliminary results indicate that we can determine the spatial and temporal variability of the accumulation rate over 


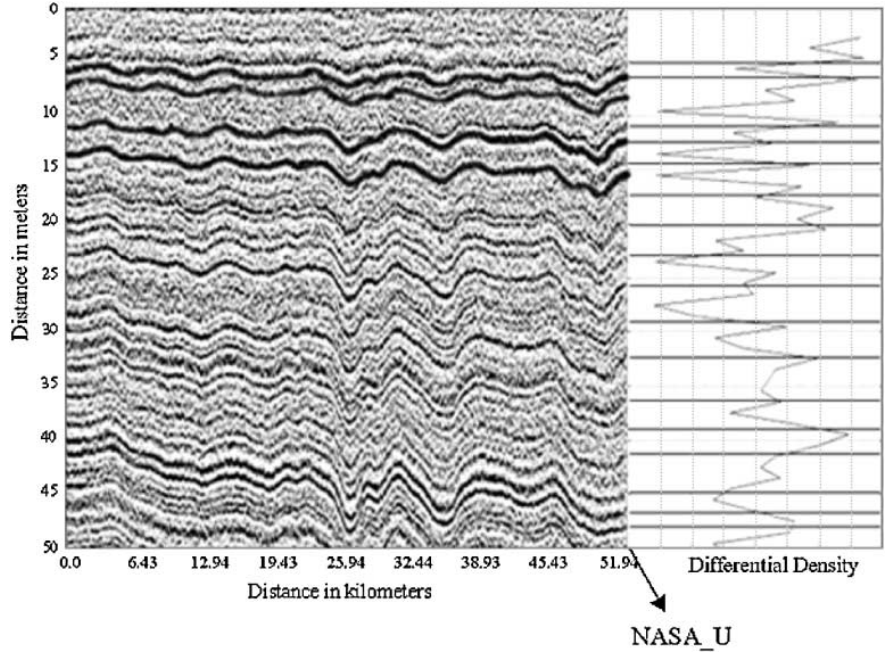

Fig. 6. Comparison between airborne radar measurements and ice core records.

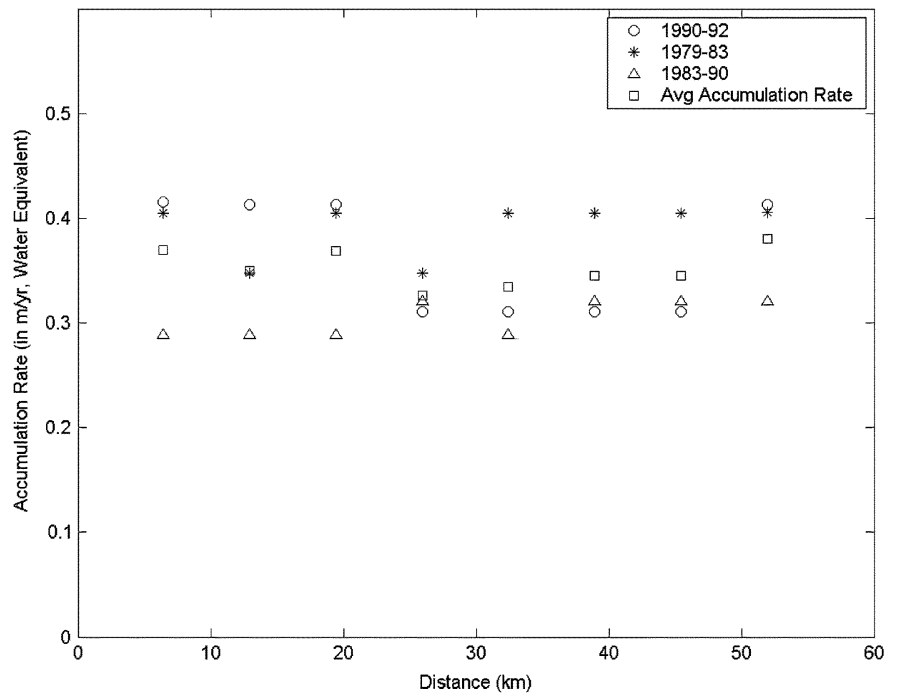

Fig. 7. Accumulation rate along the flight line (distance in kilometers) derived from radar echogram as shown in Fig. 6.

large areas of the ice sheet. We are continuing to process additional data sets collected during the 2002 and 2003 field seasons that include flight lines passing over two or more locations where ice core data are available.

\section{CONCLUSION}

The accumulation rate of polar ice sheets is an important parameter required for mass balance computations and the assessment of ice sheet contribution to sea level rise. Present accumulation maps have relatively large uncertainties in many areas due to sparse sampling in these regions. Accumulation rates are currently determined using ice cores and pits, but ice core retrieval is an expensive and tedious process. It is, thus, prudent to seek remote sensing techniques to assist in the interpolation between ice core locations to reduce the uncertainty associated with the sparse sampling.

We designed and developed a wideband radar operating over the frequency range from 600-900 MHz for airborne mapping of near-surface internal layers of an ice sheet. We operated this radar on the NASA P-3 aircraft during the 2002 field season and collected data over different zones of the Greenland ice sheet. Our results show that the radar can successfully map near-surface layers to a depth of $200 \mathrm{~m}$ in the dry-snow zone, $120 \mathrm{~m}$ in the percolation zone, nd $20 \mathrm{~m}$ in the melt zone.

We compared our radar measurements with an ice core obtained at the NASA-U_1 site. The radar-determined water equivalent accumulation rate of $34.9 \pm 5.1 \mathrm{~cm} /$ year agreed very well with the core-derived accumulation rate of $34.6 \mathrm{~cm} /$ year. We also showed that the spatial and temporal variability of accumulation can be obtained by tracking layers in radar data, which are identified using information from an ice core. Thus, we can combine radar data with density information from ice cores to study spatial and temporal variation of the accumulation rate over large areas of the ice sheet.

\section{ACKNOWLEDGMENT}

The authors would like to thank NASA for the support provided for this project under the management of W. Abdalati. They would also like to thank R. Bales (University of Arizona) for providing the ice core data and K. Mason for help in the preparation of the manuscript. They would additionally like to thank the aircraft crew and support staff at NASA's Goddard Space Flight Center Wallops Flight Facility for their help with the installation of the radar and collection of data over the Greenland ice sheet. Finally, the authors would like to thank the anonymous reviewers, whose comments and suggestions contributed to improving this paper.

\section{REFERENCES}

[1] R. Etkins and E. S. Epstein, "The rise of global mean sea level as an indication of climate change," Science, vol. 215, pp. 287-289, Jan. 15, 1982.

[2] "Climate change 2001: Impacts, adaptation, and vulnerability (summary for policy makers)," Intergovernmental Panel on Climate Change (IPCC), Geneva, Switzerland, Feb. 13-16, 2001.

[3] T. S. Perry, "Capturing climate change," IEEE Spectrum, vol. 39, pp. 58-65, Jan. 2002.

[4] M. B. Dyurgerov and M. F. Meier, "Year-to-year fluctuations of global mass balance of small glaciers and their contribution to sea-level changes," Arctic Alpine Res., vol. 29, no. 4, pp. 392-402, 1997.

[5] C. J. van der Veen and J. F. Bolzan, "Interannual variability in net accumulation on the Greenland ice sheet: Observations and implications for mass balance measurements," J. Geophys. Res., vol. 104, no. D2, pp. 2009-2014, 1999

[6] J. R. McConnell, G. Lamorey, E. Hanna, E. Mosley-Thompson, R. C. Bales, D. Belle-Oudry, and J. D. Kyne, "Annual net snow accumulation over southern Greenland from 1975 to 1998," J. Geophys. Res., vol. 106, no. D24, pp. 33 827-33 838, 2001.

[7] C. H. Davis, C. A. Kluever, B. J. Haines, C. Perez, and Y. Yoon, "Improved elevation change measurement of the southern Greenland ice sheet from satellite radar altimetry," IEEE Trans. Geosci. Remote Sensing, vol. 38, pp. 1367-1378, May 2000.

[8] W. S. B. Paterson, The Physics of Glaciers. Oxford, U.K.: Butterworth-Heinemann, 1998.

[9] A. Ohmura and N. Reeh, "New precipitation and accumulation maps for Greenland,” J. Glaciol., vol. 37, no. 125, pp. 140-148, 1991.

[10] R. C. Bales, J. R. McConnell, E. Mosley-Thompson, and G. Lamorey, "Accumulation map for the Greenland ice sheet: 1971-1990," Geophys. Res. Lett., vol. 28, no. 15, pp. 2 967-2 970, 2001.

[11] R. C. Bales, J. R. McConnell, E. Mosley-Thompson, and B. Csthao, "Accumulation over the Greenland ice sheet from historical and recent records,” J. Geophys. Res., vol. 106, no. D24, pp. 33 813-33 826, 2001. 
[12] C. U. Hammer, "Acidity of polar ice cores in relation to absolute dating, past volcanism, and radio-echoes," J. Glaciol., vol. 25, no. 93, pp. 359-372, 1980.

[13] P. Kanagaratnam, S. Gogineni, N. Gundestrup, and L. Larsen, "Highresolution radar mapping of internal layers at the North Greenland Ice core project," J. Geophys. Res., vol. 106, no. D24, pp. 33 799-33 812, 2001.

[14] S. Gogineni, T. Chuah, C. Allen, K. Jezek, and R. K. Moore, "An improved coherent radar depth sounder," J. Glaciol., vol. 44, no. 148, 1998.

[15] M. Dishal, "Gaussian-response filter design," Elect. Commun., vol. 36, no. 1, pp. 3-26, 1959.

[16] G. Athial, private communication, 2001.

[17] B. Parthasarathy, T. Plummer, and P. Kanagaratnam, "Target simulator to calibrate wideband radar in measuring the internal layers of the Greenland ice sheet," Geosci. Remote Sensing Lett., 2004, to be published.

[18] S. Gogineni, T. Chuah, C. Allen, K. Jezek, and R. K. Moore, "An improved coherent radar depth sounder," J. Glaciol., vol. 44, no. 148, 1998.

[19] W. Krabill, E. Frederick, S. Manizade, C. Martin, J. Sonntag, R. Swift, R. Thomas, W. Wright, and J. Yungel, "Rapid thinning of parts of the southern Greenland ice sheet," Science, vol. 283, pp. 1 522-1 524, Mar. $5,1999$.

[20] C. S. Benson, "Stratigraphic studies in the snow and firn of the Greenland ice sheet," U.S. Army Cold Regions Res. Eng. Lab. (CRREL), Hanover, NH, Res. Rep. 70, 1962.

[21] F. T. Ulaby et al., Manual of Remote Sensing. Bethesda, MD: Amer. Soc. Photogramm. Remote Sens., vol. 1.2, ch. 4.

[22] M. Anklin, R. C. Bales, E. Mosley-Thompson, and K. Steffen, "Annual accumulation at two sites in northwest Greenland during recent centuries," J. Geophys. Res., vol. 103, no. D22, pp. 28 775-28 783, 1998.

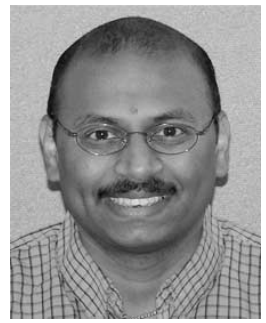

Pannirselvam Kanagaratnam (M'03) was born in Petaling Jaya, Malaysia, in 1971. He received the B.S., M.S., and Ph.D. degrees in electrical engineering from the University of Kansas, Lawrence, in 1993, 1995, and 2002, respectively.

$\mathrm{He}$ is currently a Research Assistant Professor with the Radar Systems and Remote Sensing Laboratory, Information and Telecommunication Technology Center, University of Kansas. His research interests are radar remote sensing of polar ice sheets, sea ice, and land. He has participated in numerous field experiments in Greenland and Antarctica.

Dr. Kanagaratnam is a member of the American Geophysical Union. In 1998, he received a NASA Fellowship. He received the University of Kansas Graduate School's Haglund Prize for outstanding dissertation in 2003.

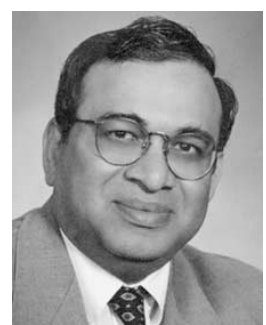

Siva Prasad Gogineni (M'84-SM'92-F'99) received the $\mathrm{Ph}$.D. in electrical engineering from the University of Kansas, Lawrence, in 1984.

$\mathrm{He}$ is currently the Deane E. Ackers Distinguished Professor in the Department of Electrical Engineering and Computer Science, University of Kansas. As a Fulbright Senior Scholar, he conducted research at the University of Tasmania, Hobart, Tasmania, from August to December 2002. He has authored or coauthored 70 archival journal publications and more than 110 technical reports and conference presentations. His research interests include the application of radars to the remote sensing of the polar ice sheets, sea ice, ocean, atmosphere, and land.

Dr. Gogineni is a member of URSI, the American Geophysical Union, the International Glaciological Society, and the Remote Sensing and Photogrammetry Society. From 1994 to 1997, he served as the Editor of the IEEE Geoscience and Remote Sensing Society Newsletter. He received a Best-of-Session Award from the Third International Airborne Remote Sensing Conference in 1997 and the Taylor \& Francis Publishers Award for Best Letter published in the International Journal of Remote Sensing in 1991.

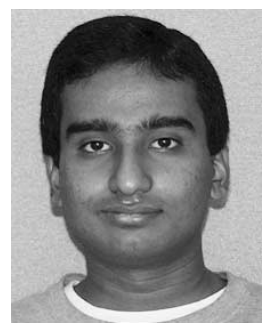

Vijay Ramasami (S'03) was born in Salem, India on September 22, 1978. He received the B.E. degree in electronics and communication engineering from Anna University, Chennai, India, and the M.S.E.E. degree (with honors) from the University of Kansas, Lawrence, where he is currently pursuing the Ph.D degree.

From June 1999 to June 2000, he was a DSP Engineer with Lucent Technologies, India, where he worked on software development for $3 \mathrm{G}$ Wireless Communication Systems. He served as a Research Assistant with the Radar Systems and Remote Sensing Laboratory, University of Kansas from August 2000 to August 2001, where he was involved in the development of an ultrawideband radar for detecting vehicles on railroad crossings. From August 2001 to December 2001, he served as a Teaching Assistant at the University of Kansas. Since 2001, he has been with the Radar Systems and Remote Sensing Laboratory, University of Kansas, where he is currently involved in the development of model-based data inversion and clutter rejection algorithms for high-resolution radar systems over glacial ice.

Mr. Ramasami was awarded the NASA Earth System Sciences (ESS) Fellowship in 2003

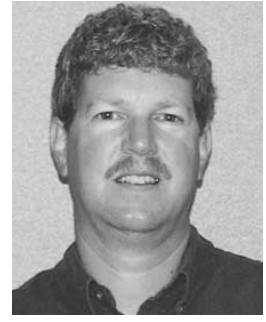

David Braaten received the B.S. degree from the State University of New York, Oswego, in 1977, and the M.S. degree from San Jose State University, San Jose, CA, in 1981, both in meteorology, and the $\mathrm{Ph} . \mathrm{D}$. degree in atmospheric science from the University of California, Davis, in 1988.

$\mathrm{He}$ is currently an Associate Professor in the Geography Department, University of Kansas, Lawrence where he has taught atmospheric science since 1989 . He is also a member of the University of Kansas Radar Systems and Remote Sensing Laboratory (RSL). He maintains an active interest in snow accumulation processes of glaciers and ice sheets using in situ measurements, remote sensing, and meteorological forecast models to assess temporal and spatial variability of snow accumulation. He has conducted several field expeditions to Antarctica, Greenland, and an alpine glacier. 